\title{
LEVEL OF KNOWLEDGE OF AGRICULTURAL EXTENSION AGENTS IN GIZA GOVERNORATE ABOUT BIRD FLU
}

( Received:18 . 9. 2006 )

\author{
By \\ S. A. M. Hikel \\ Department of Rural Sociology and Agricultural Extension, Faculty of Agriculture, Cairo University
}

\begin{abstract}
Bird flu is the most serious agricultural crisis which faced Egypt in recent time. It needed to mobilize efforts of many Ministries together with the Ministry of Agriculture to decrease economic effects of bird flu. Agricultural Extension Agents (AEA) can play an effective role to decrease of diffusion of bird flu by change of behaviors of rural people that work in home poultry production. The diffusion of bird flu between poultry and birds or from poultry and birds to human is a result of false practices of those who work in poultry production, so AEA can play their roles efficiently by knowing information related of bird flu and ways of decrease of diffusion and how to apply. This means the AEA can not change of behavior about poultry and birds production without having enough knowledge about the bird flu.

The main objectives of this study were:

- To measure the level of knowledge of AEA about bird flu.

- To determine the relationships between the level of knowledge of (AEA) with some independent variables.

- To identify the sources of information about bird flu.

The study was conducted in the Districts of Giza Governorate. Data were collected during personal interviews with AEA by using a questionnaire designed and pre-tested for the purposes of the study. The study covered a sample of (116) AEA representing (70.3\%) of the total population of AEA in Giza Governorate (165). The sample size was determined according to Krejcie and Morgan (1970) equation.

Percentages, range, frequencies, arithmetic mean, standard division, Chi square test and Pearson's correlation coefficient were used for data presentation and analysis.

The results of the study are summarized as follows:

- $(56 \%)$ of the respondents were found in the low level of knowledge.

- Statistically significant relationships were found between the level of knowledge of AEA and:

* Educational qualification.

* Existing of farm of poultry and birds in village.

* Number of farm of poultry and birds in village

- T.V and Radio were the most important information sources for AEA about bird flu.
\end{abstract}

Key words: bird flu, knowledge, Giza.

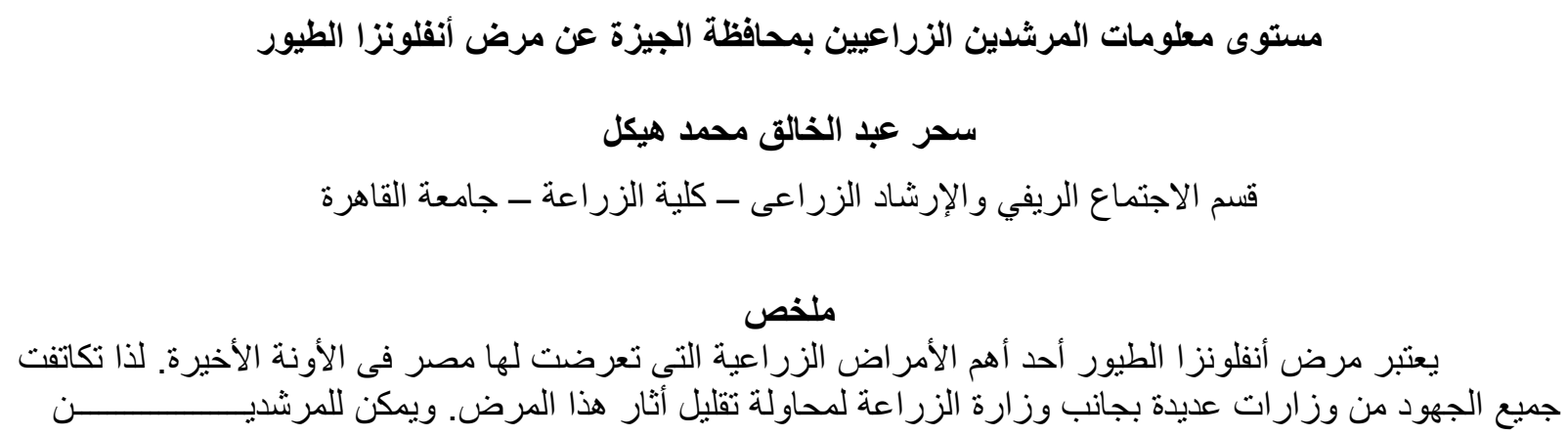




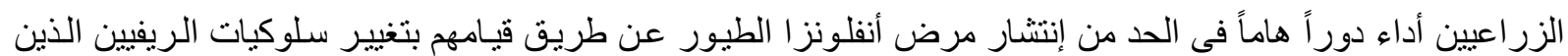

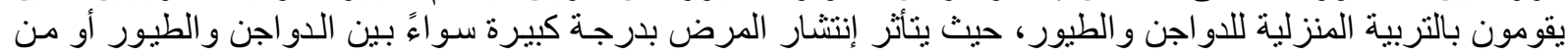

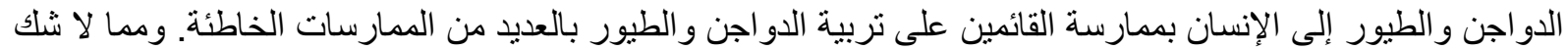

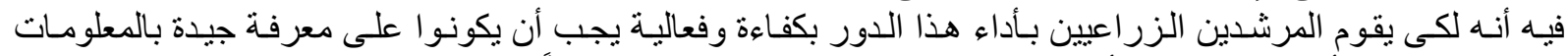

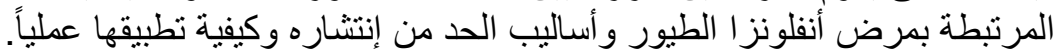

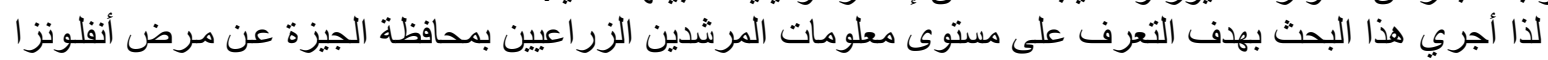

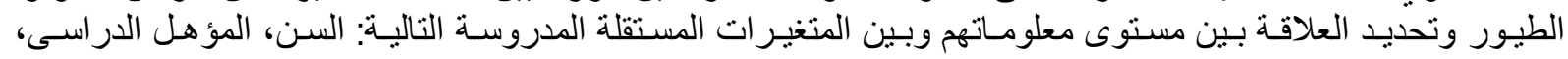

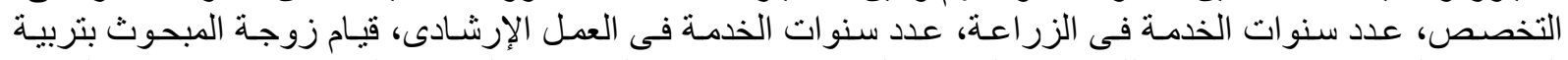

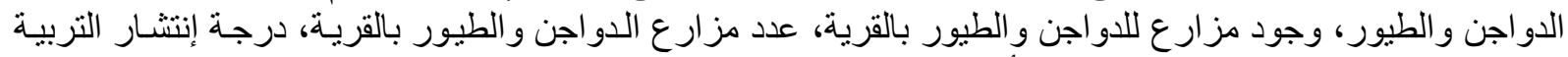

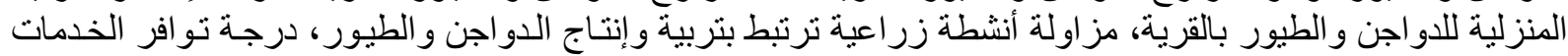

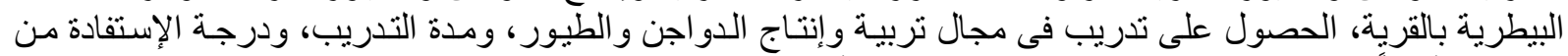

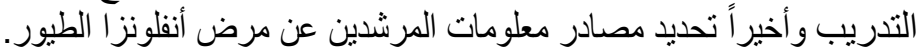

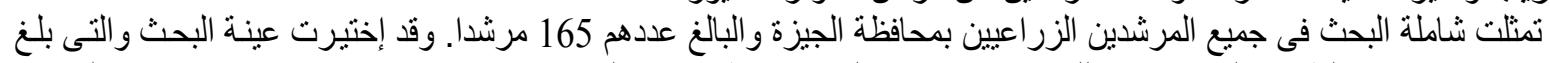

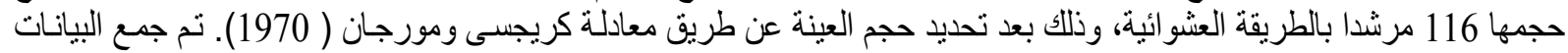

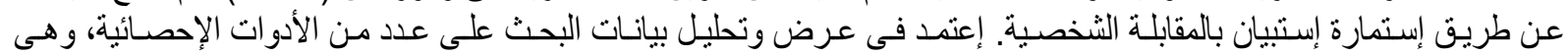

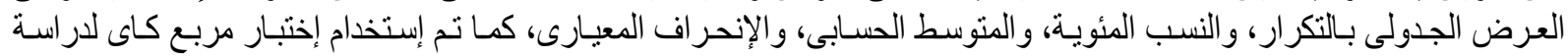

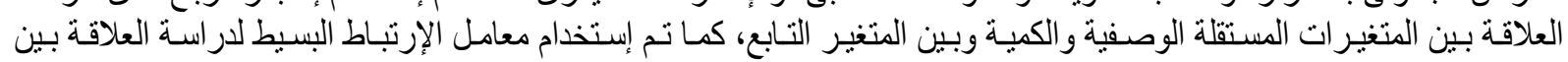

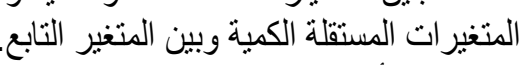

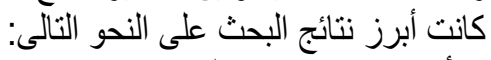

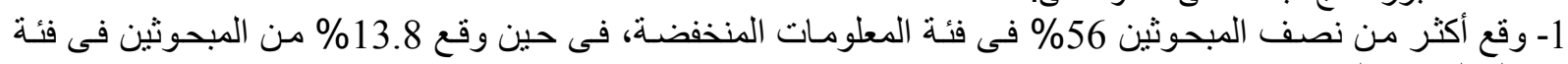

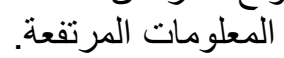

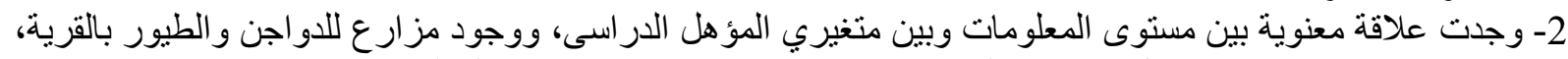

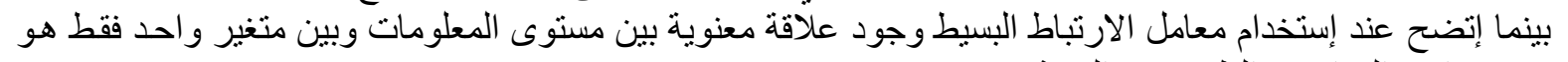

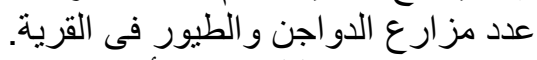

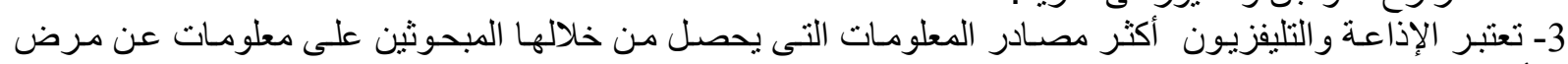
أنفلونزا الطيور الإعة و

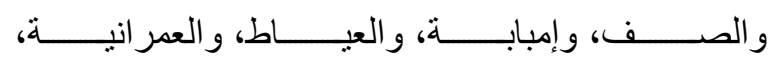
(2006) www.birdflu.sis.gov.eg وقد أثر ظهور مرض أنفلونزا الطيور بشكل كبير

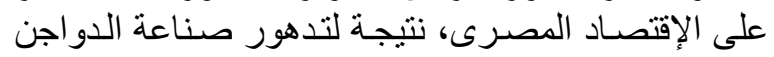

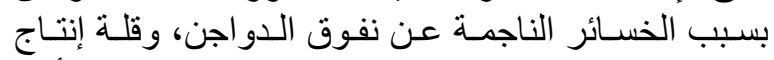

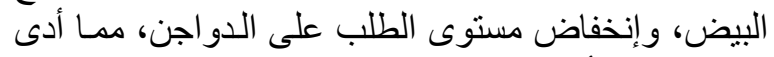

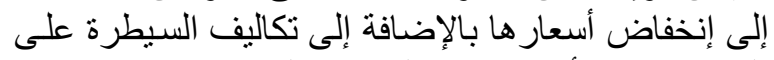

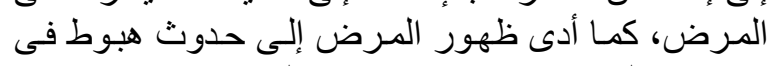

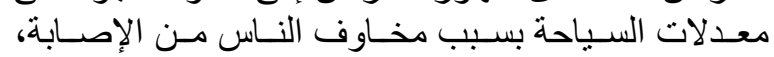

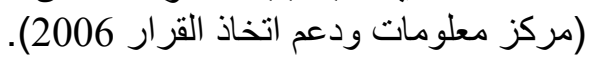

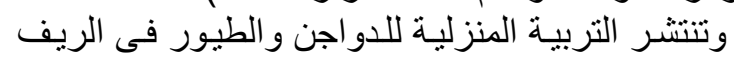

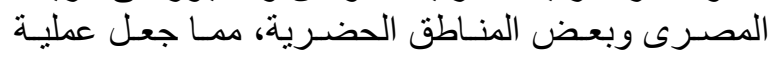

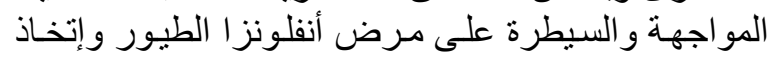

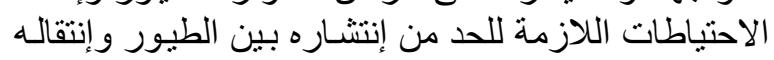
إلى البشر أمر شديد الصعوبة.

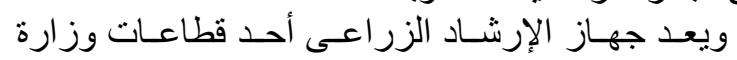

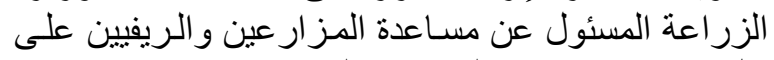

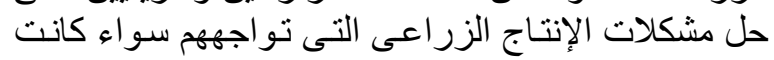

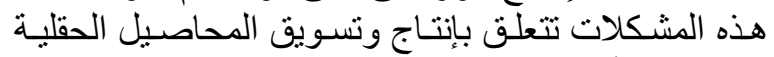

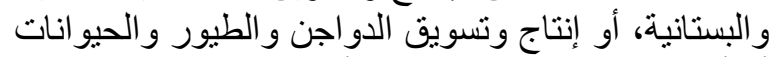

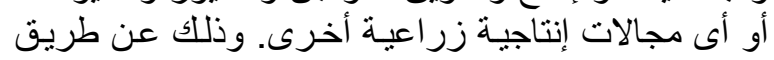
المرشدين الزر اعيين الموجودين على مستوى أنى

\section{1- المقدمة والمشكلة البحثية}

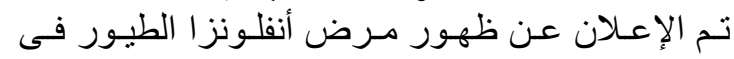

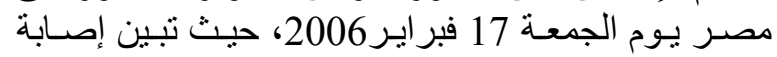

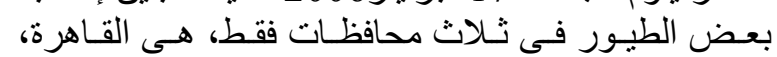

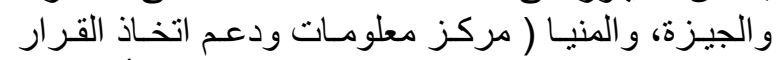

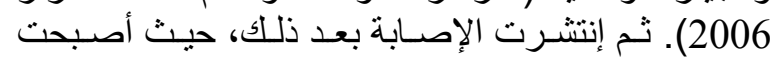

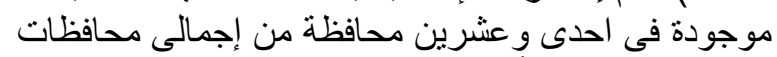

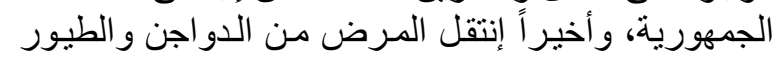

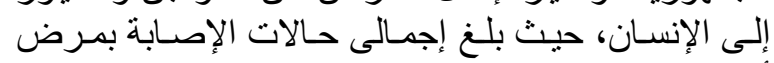

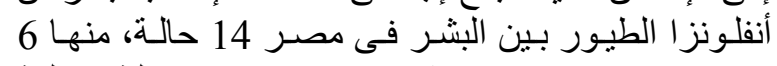

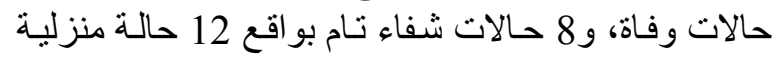

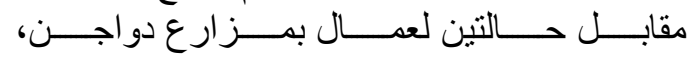
. (2006) www.birdflu.sis.gov.eg تعتبر محافظة الجيزة إحدى اكبر المحافظات من حيث

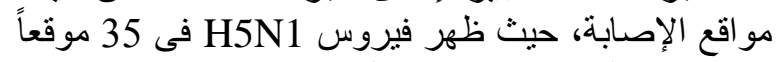

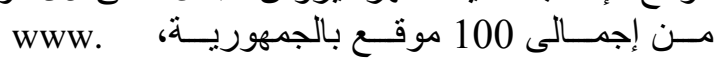
arabic.cnn.com.

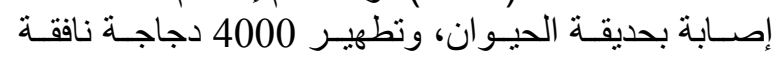

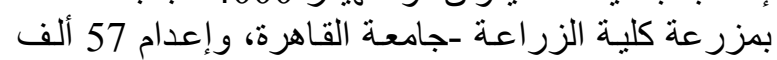

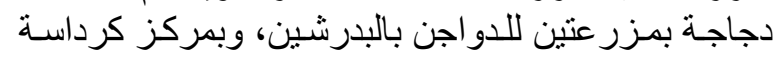

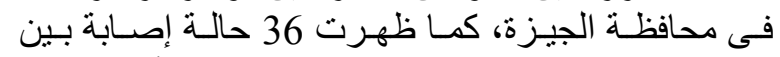
الطيور فى مز ارع بمناطق حى الهرم، ومنشـأة القناطر، 


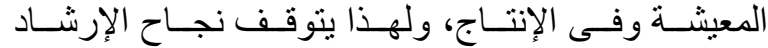

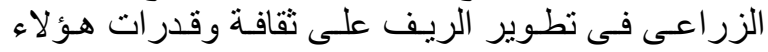

المرشدين الزراعيين ( عمر، 1965).

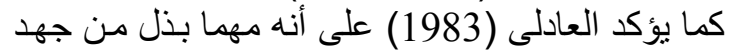

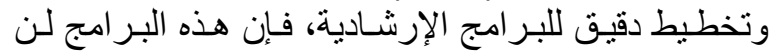

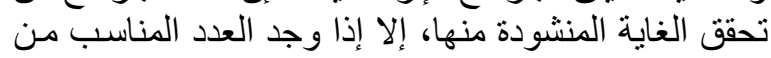

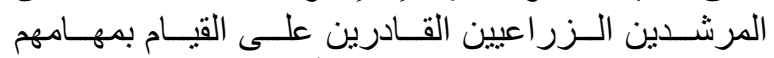

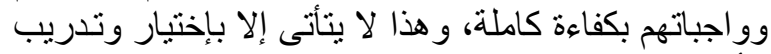
الأعداد الكافية من هؤلاء المرشدين.

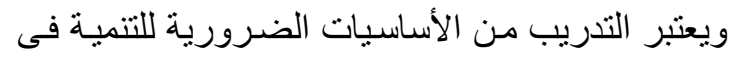

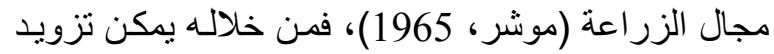

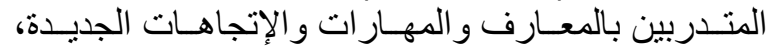

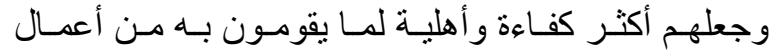
(Egyptian International Center for

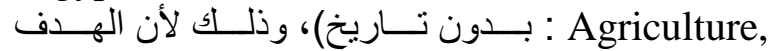
الأساسى من عملية التدريب هو إحداث تغييرات ولثي في الفرد

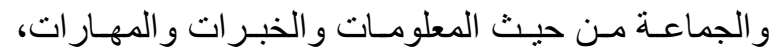

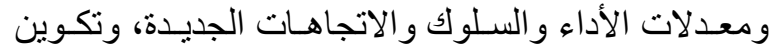

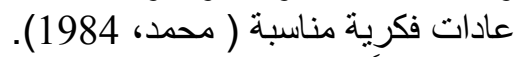

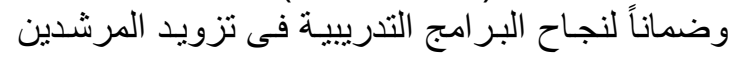

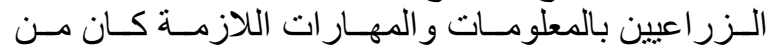

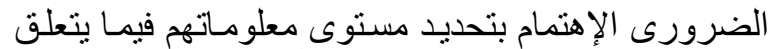

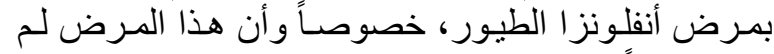
يكن منتشر اً بهذا الحجم في السنوري السنو ات الماضية.

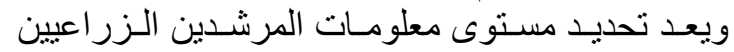

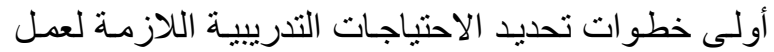

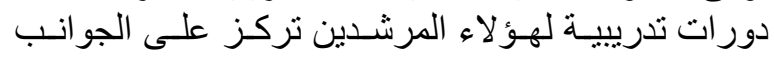

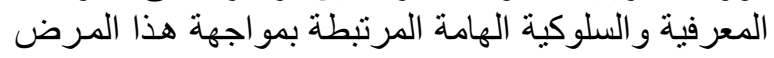

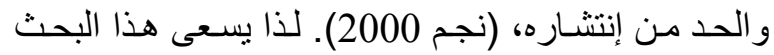
إلى الإجابة على التساؤلات النالية:

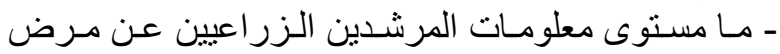
أنفلونز ا الطيور؟ مئو

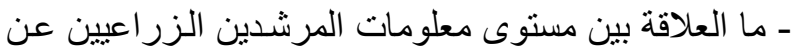

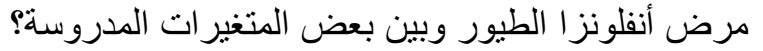

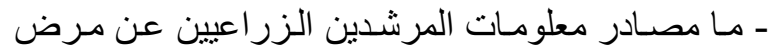

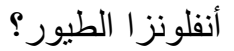

$$
\begin{aligned}
& \text { 2- الأهداف البحثية } \\
& \text { مـن العـرض المشكلى السـابق يمكن إيجـاز أهداف } \\
& \text { البحث فيما يليى : العزئ }
\end{aligned}
$$

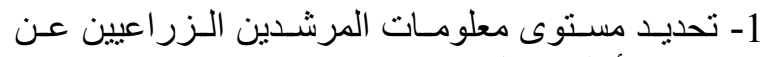

$$
\begin{aligned}
& \text { مرض أنفلونزا الطيور . مرئ }
\end{aligned}
$$

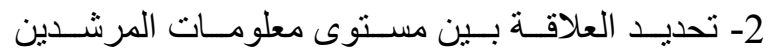
الزر اعيين عن مرض أنفلونز الطيور الطيور (كمتغير تابع)

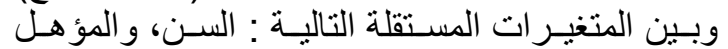

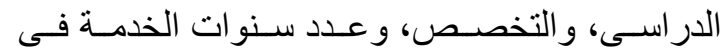
الزر اعة، و عدد سنوات الخدمة فى وعى

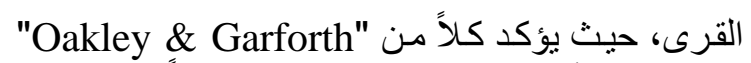

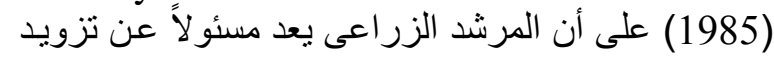

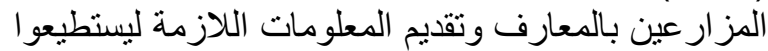

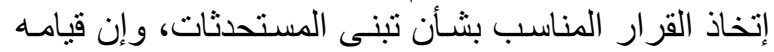

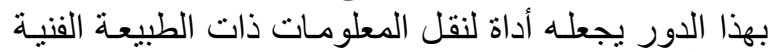

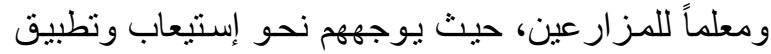
تلك المعلومات التى يقوم بنقلها.

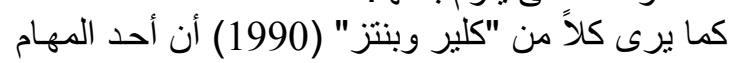

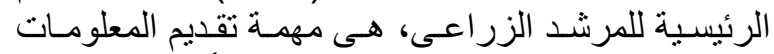

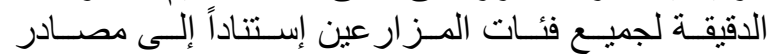
المعلومات الموثوق بهاو غئر المبر المتحيزة.

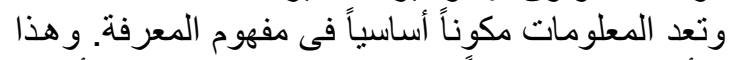

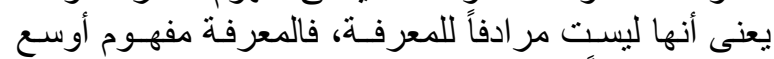

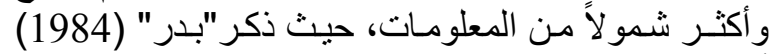
أن المعلومات هى وسيلة تغيير الحالة المعرفية للإنسان.

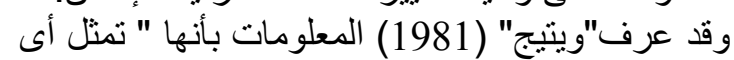

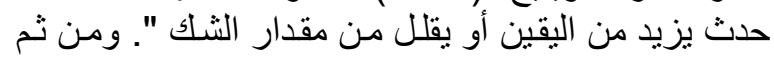

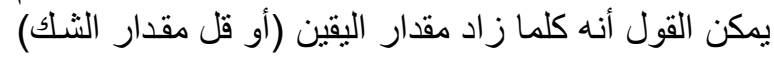

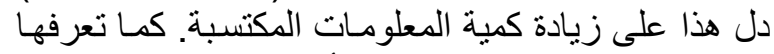

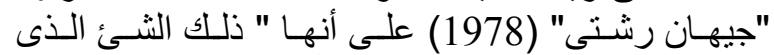

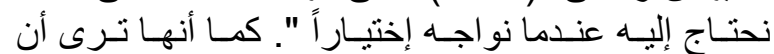

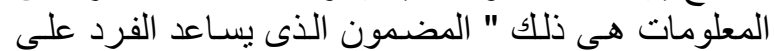

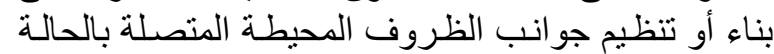

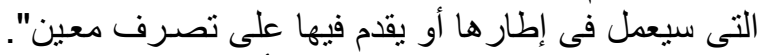

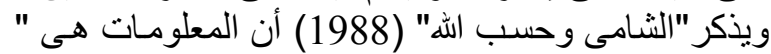

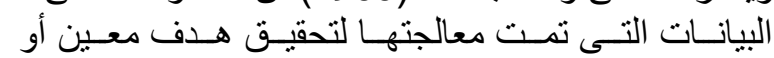

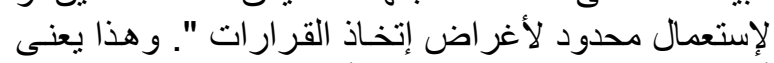

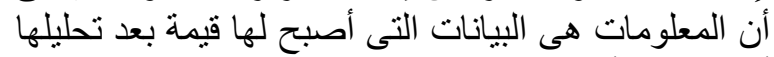

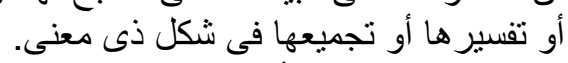

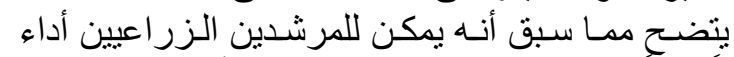

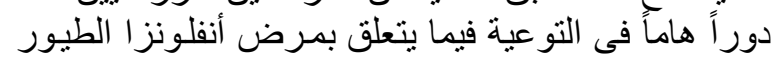

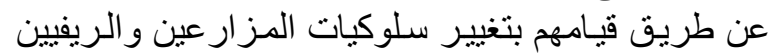

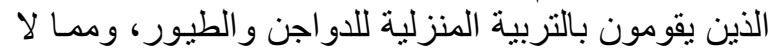

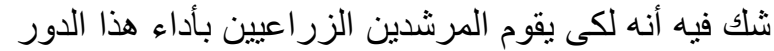

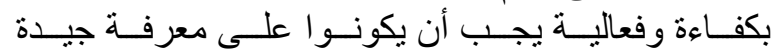

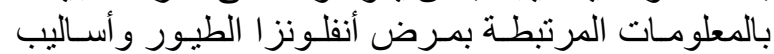
الحد من إنتشاره وكيفية تطبيقها عملياً.

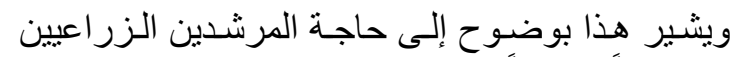

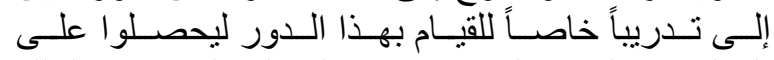

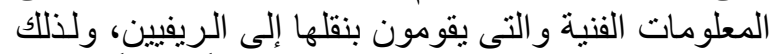

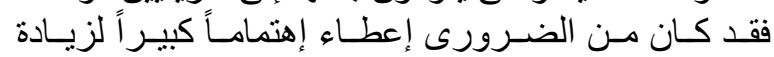

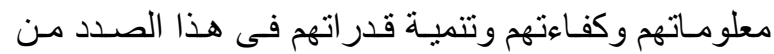

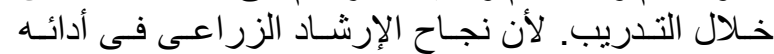

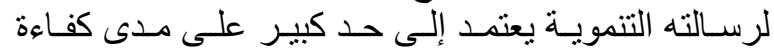

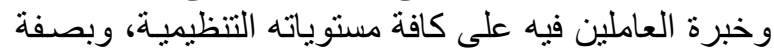

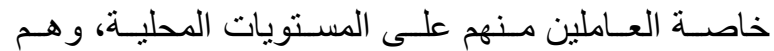

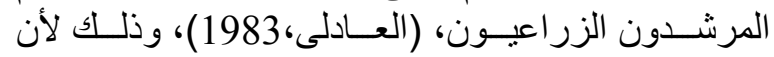

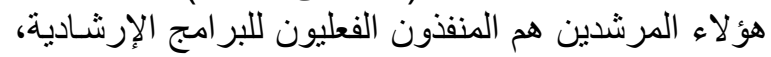

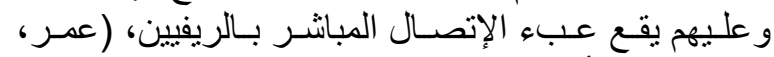

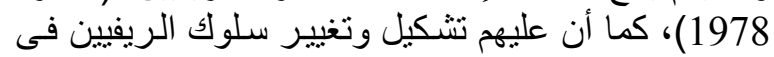




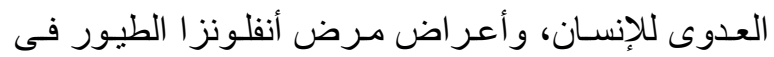

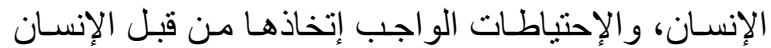

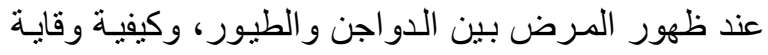

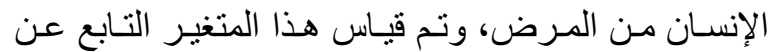

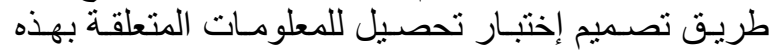

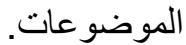

للتعرف على علاقة المتغير التابع بالمتغير ات المستقلة

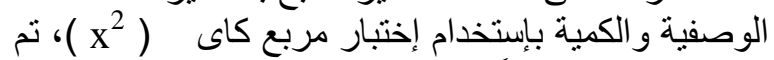

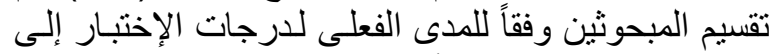

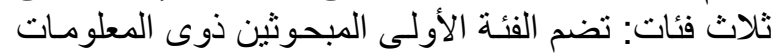

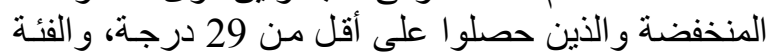

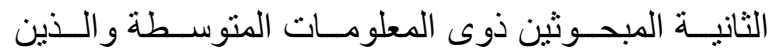

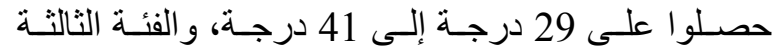

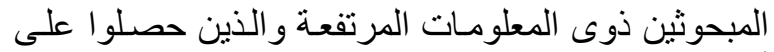

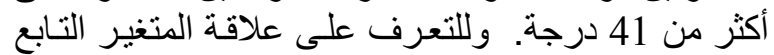

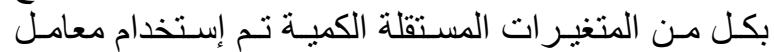
الإرتباط البسيط . البغنرات

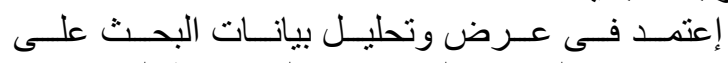

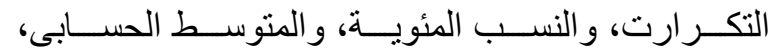

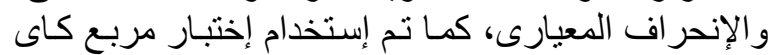

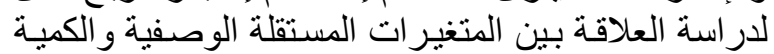

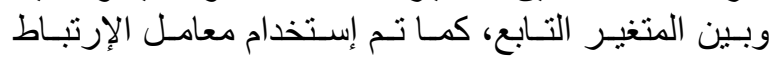
البسيط لدر اسة العلاقة بين المتغير التير المستقلة الكمية وبين الإنين

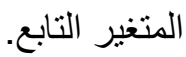

\section{4-النتائج ومناقشتها}

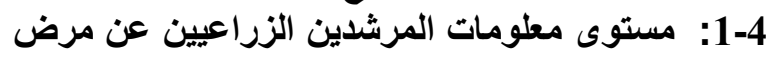
انفلونزا الطيور

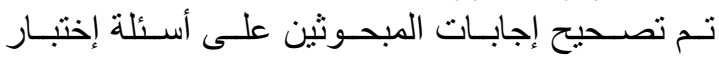

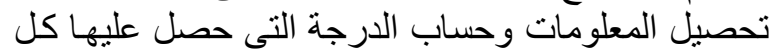

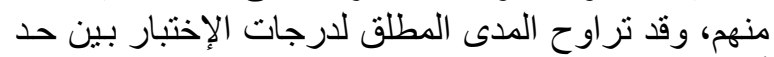

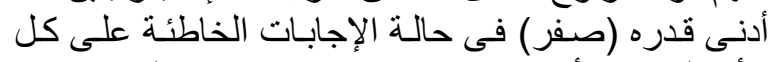

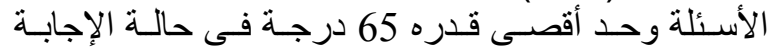

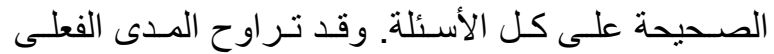

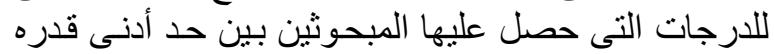

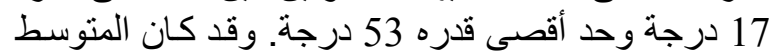

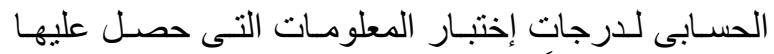
المبحوثين مساوياً 23.04 درجة، و إنحر الف معيارى قدره

56 وضح بيانات جدول (1) أن أكثر من نصف المبحوثين

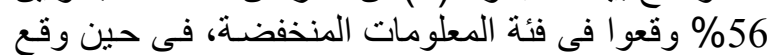

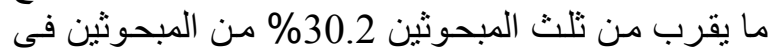

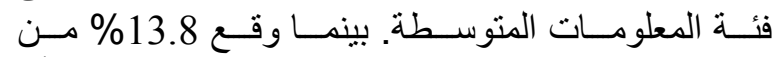

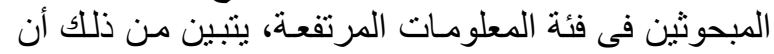

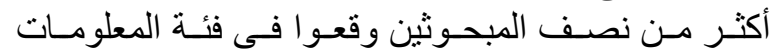

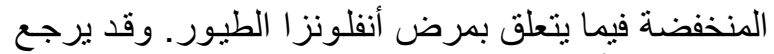
ذلك إلى قلة أو عدم الإهتمام بعقد بـن

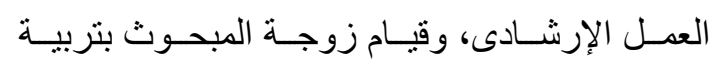

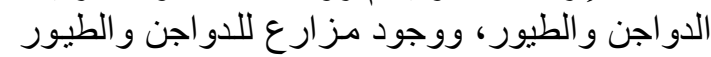

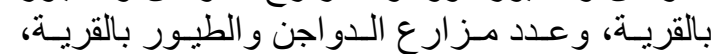

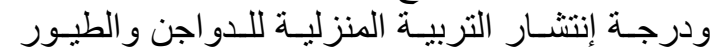

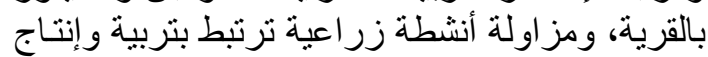

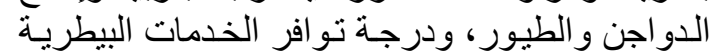

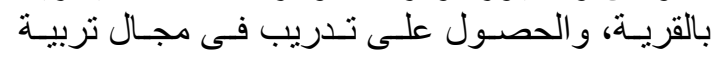

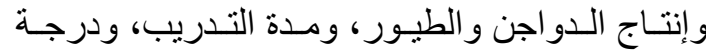
الإستفادة من التدريب.

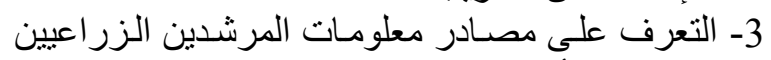

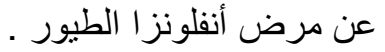

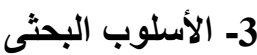

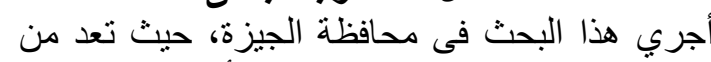
أكبر المحافظات التى إنتشر بها مرض أنفا أنفلونزا الطيور.

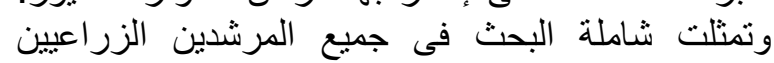

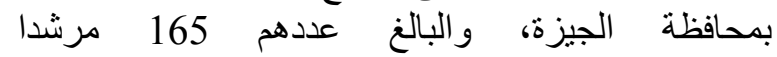

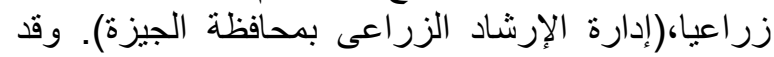

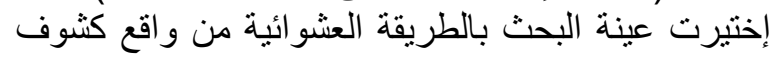
المرشدين الزراعيين بمر اكز المحافظة، وذلكية بلك بعد تحديد

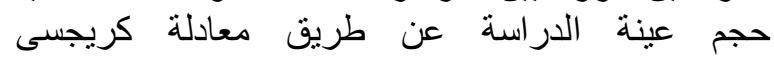

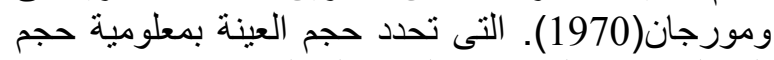

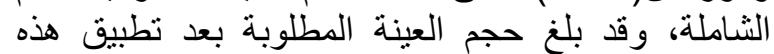

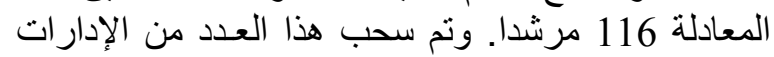

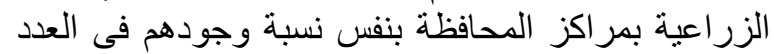

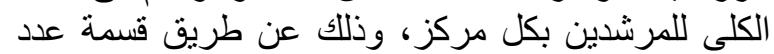

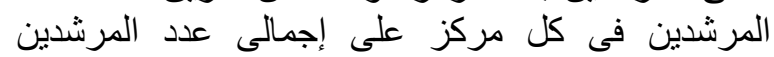

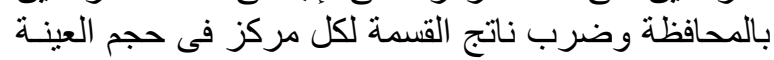

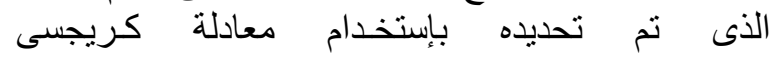
ومورجان(1970).

تم جمع البيانات عن طريق إستمارة إستبيان بالمقابلـة

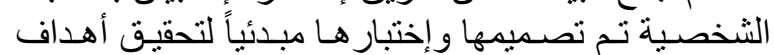

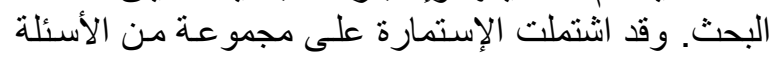

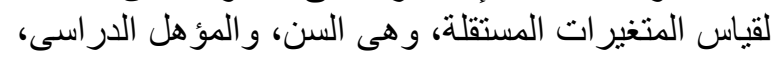

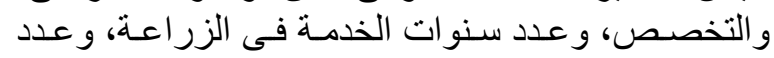

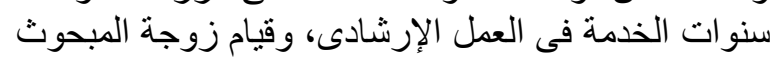

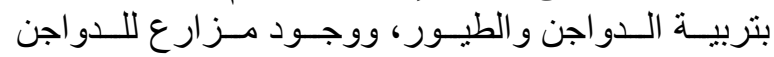

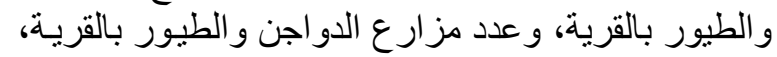

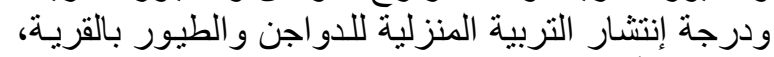

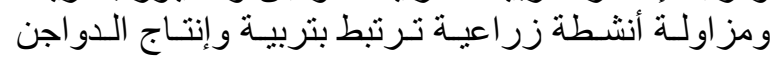

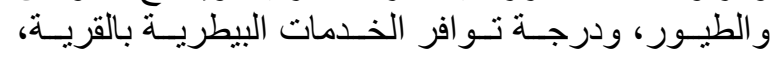

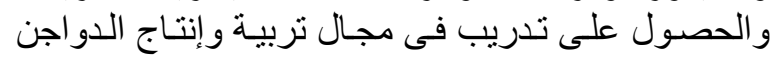

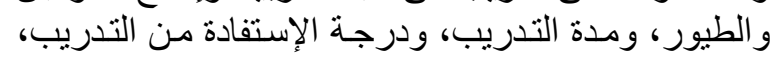

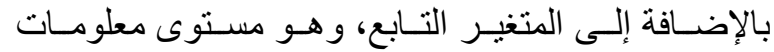

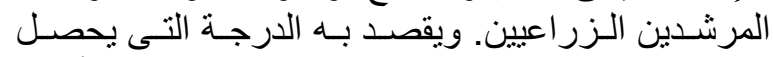

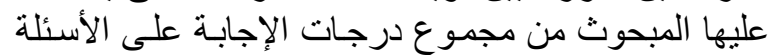

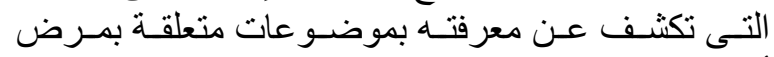

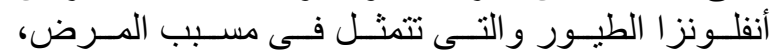

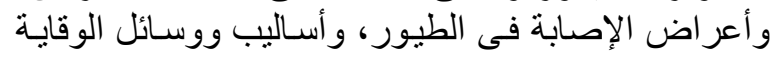

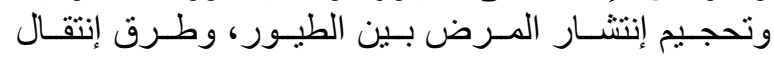


بالقريـة، ومز اولــة أنشــة زر اعيـة تـرتبط بتربيـة و إنتــاج

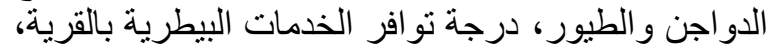

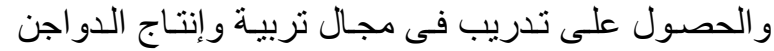
و الطيور، ومدة التدريب، ودرجة الإستفادة من التدريب.

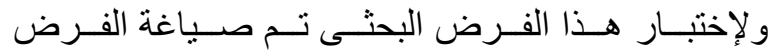

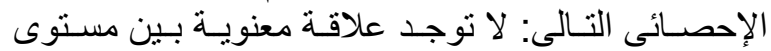

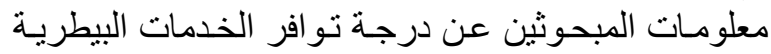

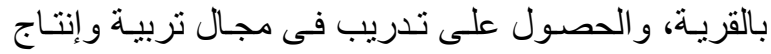

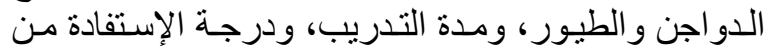

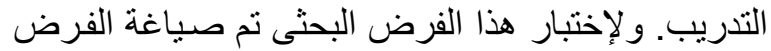

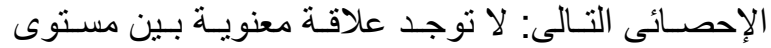

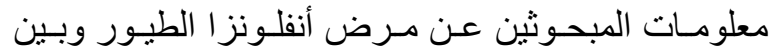

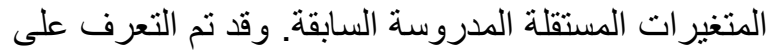

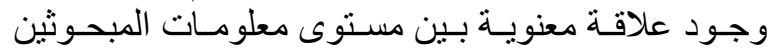

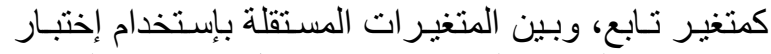

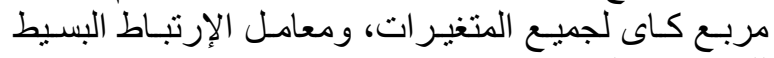
للمتغير ات الكمية منها. توضح بيانات جدول (2) أنه عند إستخدام إختبار مربع المبع

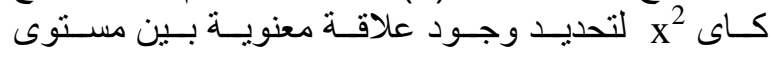

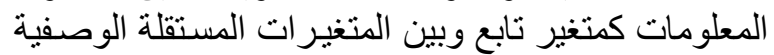

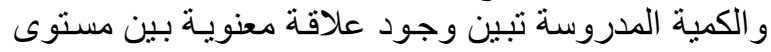

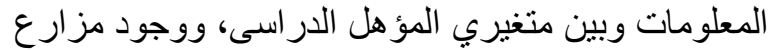
لللاو اجن و الطيور بالقرية.

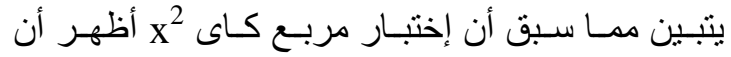

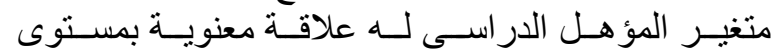

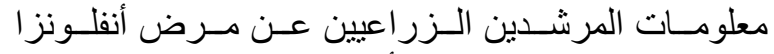

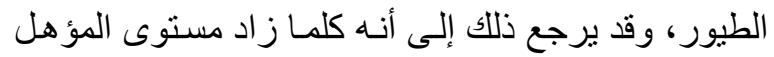

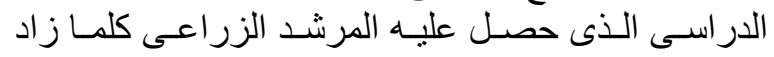

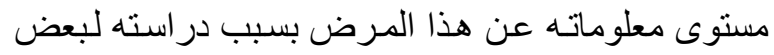

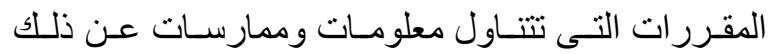
كما أظهر إختبار مربع كاى x² أن متغير وجود مزارع

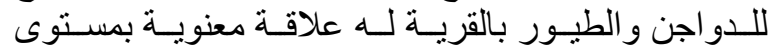

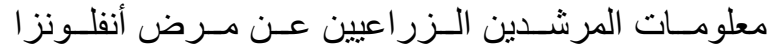

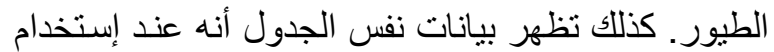

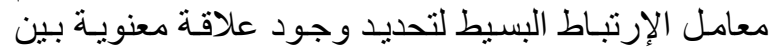

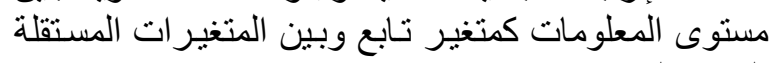

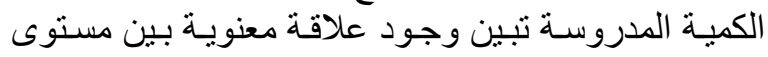

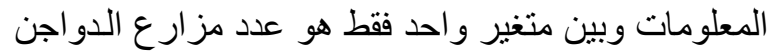
و الطيور فى القرية.

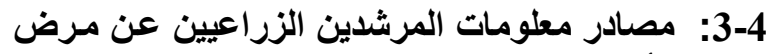
أنفلونزا الطيور

يوضـح جدول (3) أن الإذاعـة و التليفزيون هـى أكثر

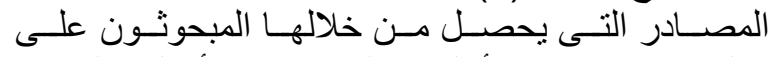

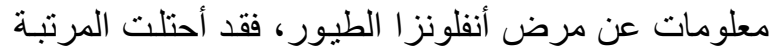

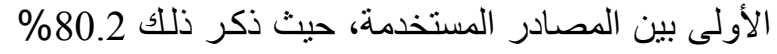

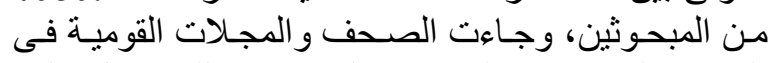

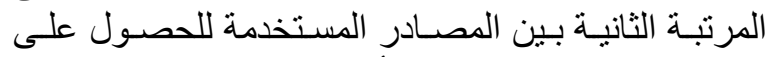
معلومات عن المرض، حيث أنثار إلى ذلك ما يقرب من لـن

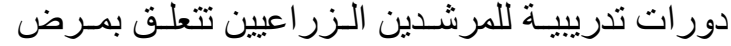

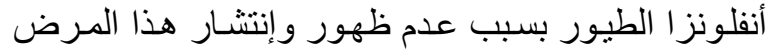

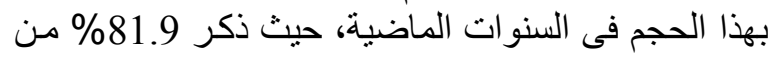
المبحوثين لم يحصلو العلى دور ات التدريبية في مجال تربية

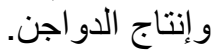

جدول (1): توزيع المبحوثين وفقا لمستوى معلوماتهم عن مرض انقلوانزا الطيور.

\begin{tabular}{|c|c|c|}
\hline$\%$ & 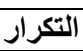 & فئات مستوى المعلومات \\
\hline 56.0 & 65 & المعلومات المنخفضة (أقل من 29 درجة) \\
\hline 30.2 & 35 & المعلومات المتوسطة (29 - 41 درجة) \\
\hline 13.8 & 16 & المعلومات المرتفعة (أكثر من 41 درجة) \\
\hline 100 & 116 & الإجمالى \\
\hline
\end{tabular}

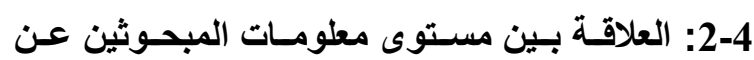

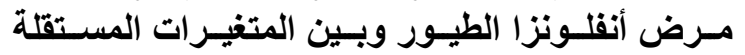
المدروسة ذانة

لتحقيق ذللك تم صياغة الفرض البحثى التالى " توجد التوند

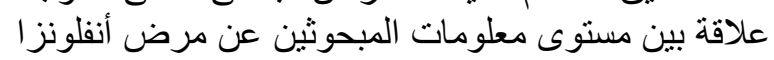

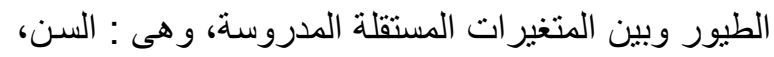

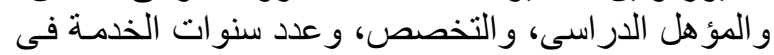

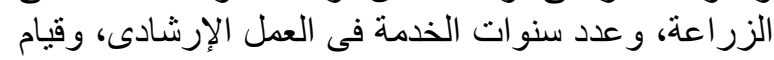

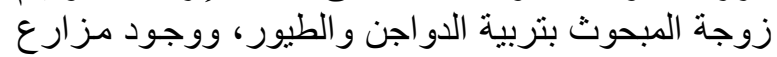

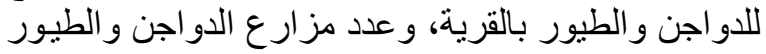

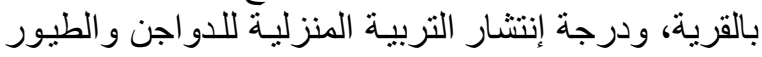

جدول (2) قيم كا2 (x²)، ومعامل الإرتباط (r) المحسوبة للمتغيرات المستقلة

\begin{tabular}{|c|c|c|c|}
\hline $\begin{array}{c}21 \text { قيمة } 21{ }^{2} \\
\left(x^{2}\right)\end{array}$ & قالارتباط معامل البسيط & المتغيرات المستقلة & b \\
\hline 0.09 & $0.048-$ & السن & 1 \\
\hline *20.19 & - & المؤهل الدراسى & 2 \\
\hline 7.096 & - & التخصص & 3 \\
\hline 0.67 & $0.042-$ & الزر اعد سنوات الخدمة فىى & 4 \\
\hline 3.20 & 0.092 & الإرشادى سنو ات الخدمة فى العمل & 5 \\
\hline 3.87 & - & قالدام زوجة المبحوث بتربية & 6 \\
\hline *19.24 & - & وجالقرية مزر اع للدو اجن و الطيور & 7 \\
\hline 3.87 & *0.292 & بالقرية مز ارع الدو اجن والطيور & 8 \\
\hline 6.10 & 0.77 & للدرجة انتشار التربية المنزلية & 9 \\
\hline 5.40 & - & مثربية و إنتاج الدو اجن زاجنة والطيور & 10 \\
\hline 5.38 & $0.157-$ & بالقرجة توافر الخدمات البيطرية & 11 \\
\hline 4.52 & - & تربية و إنتاج الدو اجن و الطيب فيور مجال & 12 \\
\hline 3.99 & 0.034 & مدة التدريب & 13 \\
\hline 2.43 & 0.032 & درجة الاستفادة من التدريب. & 14 \\
\hline
\end{tabular}




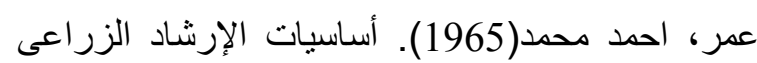
فى تطوير المجتمعات الريفية، دار النهضة العربية الزيبة، القاهرة:74. - (القير

كلير، وبنتز (1990). الهيكل التنظيمى وإدارة الإرشاد،

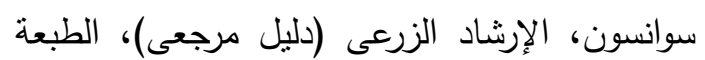

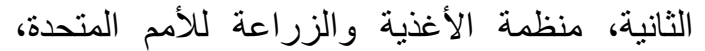
روما، إيطاليا:299.

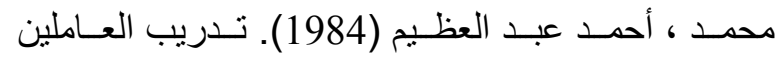

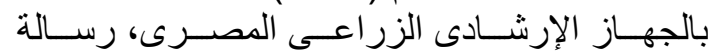

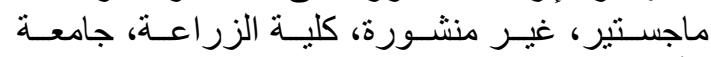
الأز هر:22.

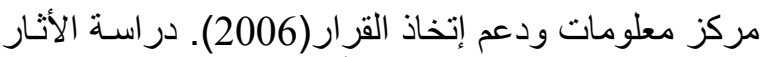

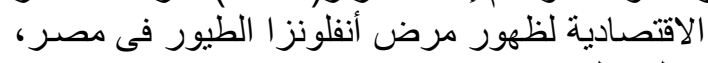
مجلس الوزر اء:3.

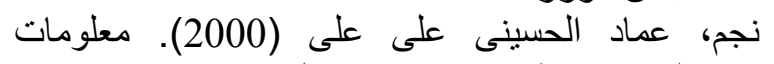
المرشدين الزراعيين فى مجال ترشيد استخدام مياه

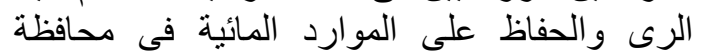

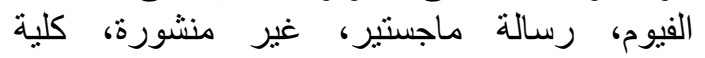

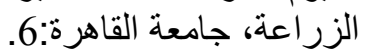

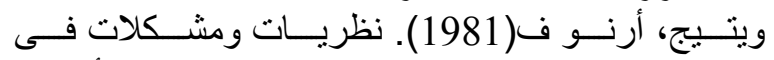
سيكولوجية التعلم، ترجمة عادل عز الدئ الدين الأشول،

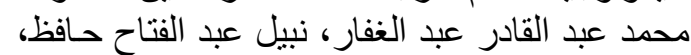

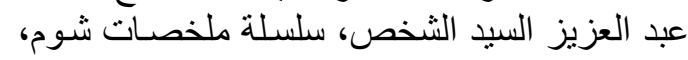
دار ماكجرو هيل للنشر ، القاهرة:227.

Egyptian International Center for Agriculture, (n.d). Course on Agricultural Services, Ministry of Agriculture and Agrarian Reform. Cairo: 67.

Krejcie, Robert and Morgan, Daryle (1970): Determining Sample Size for Research Activities in Educational and Psychological Measurements, College Station, Durham, North Carolina, U.S.A, Vol.(30).

Mosher A. T. (1965). Getting Agricultural Moving Essentials for Development and Modernization, Fredric, Appraiser Publishers New York .U.S.A: 13.

Oakley, P. and Garforth C.,(1985). Guide to Extension Training, Food and Agriculture Organization of the United Nations, Rome, Italy: 93.

www. arabic.cnn.com.20/2/2006:1.

www.birdflu.sis.gov.eg/ahtm1/flu01001.htm.18/ 12/2006: 3 .

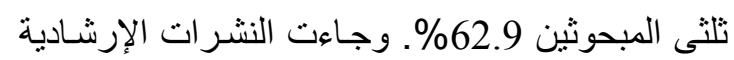

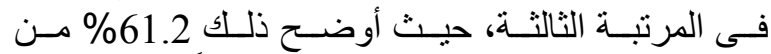
المبحوثين. بينما كان أقل المصادر إستخداماً هو الوحدات البيطرية، حيث ذكر ذلك 18.1\% من التئن المبحوثين.

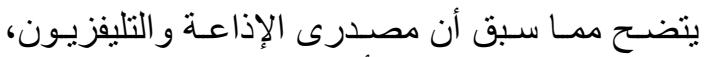

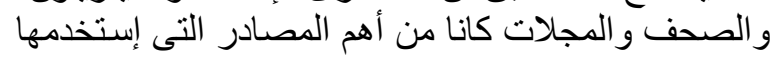

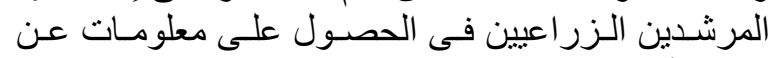

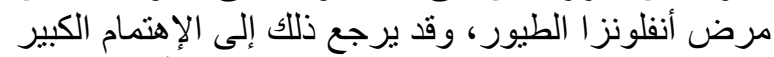

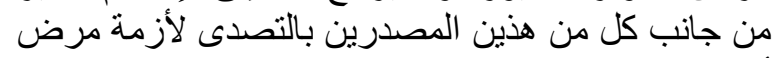

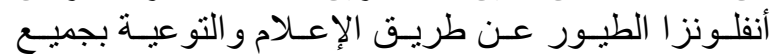

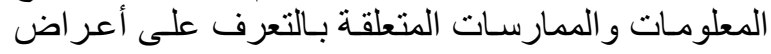

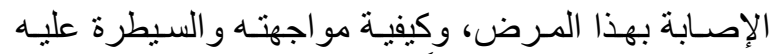

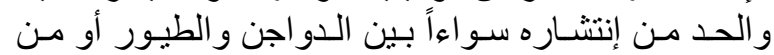

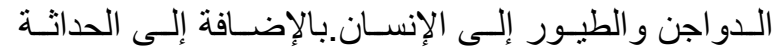

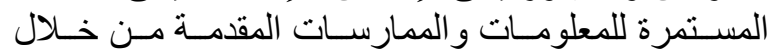

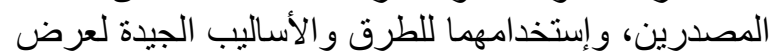

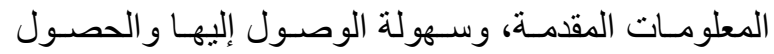
على معلومات منهما.

جدول (3): مصادر معلومات المرشدين الزراعيين عن مرض

\begin{tabular}{|c|c|c|c|}
\hline \multicolumn{4}{|c|}{ انفلونزا الطيور (ن)=116 } \\
\hline$\%$ & عدد & مصادر المعلومات & 5 \\
\hline 80.2 & 93 & الإذاعة و التليفزيون & 1 \\
\hline 62.9 & 73 & الصحف و المجلات القومية & 2 \\
\hline 61.2 & 71 & النشر ات الإرشادية & 3 \\
\hline 41.4 & 48 & المجلة الزراعية & 4 \\
\hline 20.7 & 24 & أخصائيي الإنتاج الحيو انى & 5 \\
\hline 18.1 & 21 & الوحدات البيطرية & 6 \\
\hline
\end{tabular}

إستناداً إلى النتائج السـابقة التى توصل إليها البحـث

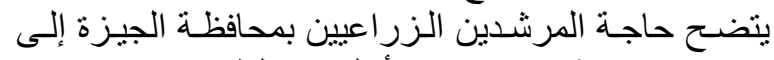

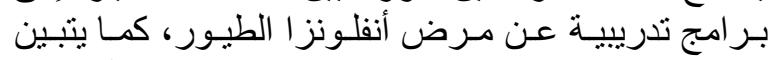

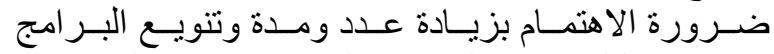

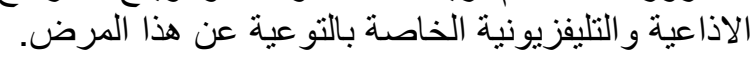

\section{5- - 5 - 5 المراجع}

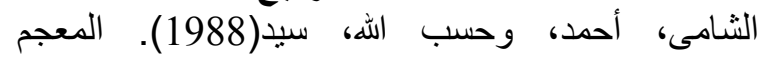

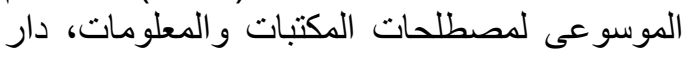

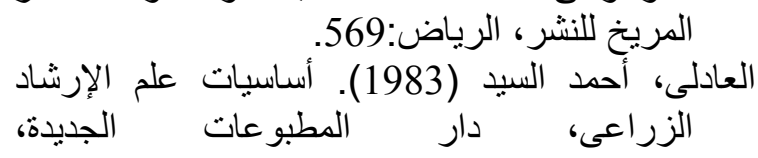
الإسكندرية:185.

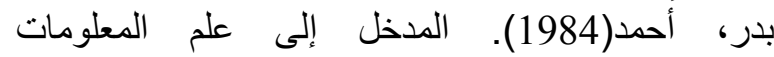

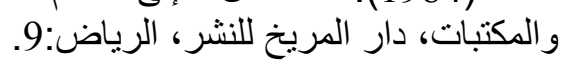

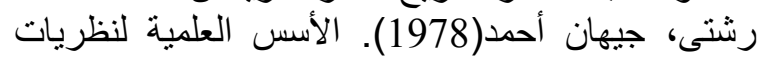

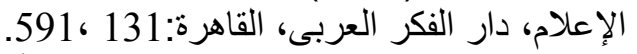

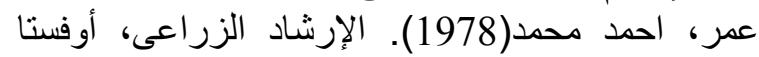

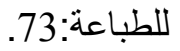

